\title{
Applied study on the rotational molding and processing technology of rotational molds
}

\author{
Alina Bianca Pop ${ }^{1,}$ and Aurel Mihail Țîțu ${ }^{2,3^{*}}$ \\ ${ }^{1}$ Technical University of Cluj-Napoca, 62A, Victor Babeș Street, Baia Mare, Romania \\ 2 "Lucian Blaga" University of Sibiu, 10 Victoriei Street, Sibiu, România \\ ${ }^{3}$ The Academy of Romanian Scientists, 54, Splaiul Independenței, Sector 5, Bucharest, Romania,
}

\begin{abstract}
Computer-aided manufacturing involves a set of computerized activities related to the preparation, launch and follow-up of manufacturing. Computer-aided manufacturing is a tool that allows the use of 3D models based on computer-aided design. This paper addresses the process of rotational formation, with an effective focus on the technology of processing a rotational mold using CAM simulation as a research method. In this sense, the right choice of $\mathrm{CNC}$ and cutting tools is essential. The use of numerically controlled machine tools and high-performance cutting tools reduces the number of operations. The manufacturing route realized is specific to the parts machining on numerical control machine, with multiple possibilities such as the execution on a single machine of all the necessary operations to create the mold. PowerMILL gives the user the flexibility to generate thisheir NC programs and ensures the use of the most efficient processing method without having to wait for the complete calculation. A number of different strategies, from the wide range that PowerMILL has, are compared using a high tolerance so that they can be calculated quickly. In this study, the strengths of the $\mathrm{CNC}$ are highlighted based on experimental research, features that make this machine a very productive one, saving time, energy and, implicitly, low execution costs.
\end{abstract}

\section{Introduction}

Rotational forming is superior to other processing methods in terms of low cost, break-even point and size of parts that can be manufactured. Often products made by rotational forming are a substitute, with a lower mass, for traditionally used materials [1]. The technology has been improved, especially in process control, materials used and mold manufacturing. The high degree of machine automation and the wide range of raw materials available allow the rotational forming process to address the most diverse applications; from small ones, such as plastisol syringes, to 87.720 liter polyethylene containers [2]. Although the concept of rotational formation is older than 150 years, the production of hollow plastic parts for various applications (such as play equipment, furniture, tanks and canisters, etc.) has been used only for the last 50 years [3].

\footnotetext{
* Corresponding author: mihail.titu@ulbsibiu.ro
} 
Since the 1990s, the production of rotational molds at the industrial level has increased every year by between 10 and $15 \%$ [4]. The mold is one of the most important parts in the process of rotational formation. Its main function is to define the final shape of the piece [5]. The molds required for the rotational forming process can be obtained from several types of materials and can be made by several methods [6]. Among the methods of obtaining and the types of materials of the rotational molds, we can mention:

- Die-cast aluminum molds;

- Aluminum dies obtained on numerically controlled machines;

- Dies made of thin steel sheet;

- Molds formed by EDM.

When manufacturing these molds on numerically controlled machines, their inner surfaces are made for the first time and the outer surfaces are further processed $[7,8]$. The operation is performed in this way, to avoid stresses that occur during processing, so the inner surfaces will not be affected and the accuracy of the cavities is maintained [9, 10]. Unlike conventional machines, an operator only needs to program the CNC machine. From the moment a CNC machine is set up, it is very simple to keep it running, the operator's task being to power the machine, but even this operation is partially taken over by CNC machines $[11,12]$. The elaboration of the processing process of a mold includes as phases: the analysis of the shop-floor drawing of the part, the choice of the type of semi-finished product, the establishment of the processing, their structuring and ordering, the establishment of the workpiece, the choice of machine tools, tools and control, establishing the machining and semi-finished parts (simulation of processing), establishing the cutting regime and processing times, programming the machine tools with numerical control [13]. In many companies, the CAM department works with the CAD department, which makes the parts models. This eliminates the need for those in the CAM department to redefine the configuration of the part [14. 15]. The CNC programmer will specify the required operations and the CAM system will create the $\mathrm{CNC}$ program. The $\mathrm{CNC}$ program is nothing more than a series of orderly instructions that the machine controller executes sequentially, step by step [16].

\section{Research methodology}

\subsection{Choosing the numerically controlled machine tool}

This paper addresses the process of rotational formation, with an effective focus on the technology of processing a rotational mold using CAM simulation as a research method. In this sense, the right choice of CNC and cutting tools is essential.

The characteristics of the OKUMA MU-400VA CNC machine [17] shown in Table 1 indicate that this machine meets the requirements for its use in the process of making a rotary mold. High positioning and repositioning accuracy as well as high feed rates are the strengths of this machine. These features make this machine a very productive one, saving time, energy, and implicitly low execution costs. The $\mathrm{CNC}$ characteristics were presented as a stage within the research methodology. The main aspects of the research is focus on FEA analysis. But, we consider that these aspects are necessary to be mentioned in the presentation of the research methodology.

Table 1. The characteristics of numerically controlled machining center Okuma MU-400VA [17]

\begin{tabular}{|c|c|c|c|}
\hline \multirow{4}{*}{ CNC travel } & X Axis & 762 & {$[\mathrm{~mm}]$} \\
\cline { 2 - 4 } & Y Axis & 460 & {$[\mathrm{~mm}]$} \\
\cline { 2 - 4 } & Z Axis & 460 & {$[\mathrm{~mm}]$} \\
\cline { 2 - 4 } & A Axis & $+20 \sim-100^{\circ}$ & {$[$ degree] } \\
\hline
\end{tabular}




\begin{tabular}{|c|c|c|c|}
\hline & C Axis & $360 \mathrm{o}$ & [degree] \\
\hline \multirow{4}{*}{ CNC table } & Table size & $\varnothing 400$ & {$[\mathrm{~mm}]$} \\
\hline & Maximum workspace size & $\varnothing 600 \times \mathrm{h} 400$ & {$[\mathrm{~mm}]$} \\
\hline & Distance from the ground to the table & 1050 & {$[\mathrm{~mm}]$} \\
\hline & Maximum load & 300 & {$[\mathrm{~kg}]$} \\
\hline \multirow{3}{*}{ Shaft } & Spindle speed function & $\begin{array}{c}8.000,15.000,20.000 \\
25.000,35.000\end{array}$ & {$\left[\mathrm{~min}^{-1}\right]$} \\
\hline & Taper hole & Taper between $7 / 24$ la 40 & \\
\hline & Diameter of support & $\varnothing 70$ & {$[\mathrm{~mm}]$} \\
\hline \multirow{3}{*}{ Feeder } & Feed $(X-Y-Z)$ & $\begin{array}{l}\mathrm{X}-\mathrm{Y}: 40 \\
\mathrm{Z}: 32\end{array}$ & {$[\mathrm{~m} / \mathrm{min}]$} \\
\hline & Feed (A-C) & $14.400-18.000$ & {$[\mathrm{o} / \mathrm{min}]$} \\
\hline & Feed rate & 32 & {$[\mathrm{~m} / \mathrm{min}]$} \\
\hline \multirow[b]{2}{*}{ Engine } & Shaft & $11 / 7.5 ; 15 / 10$ & {$[\mathrm{~kW}]$} \\
\hline & Axis loading $(X-Y-Z)$ & $\begin{array}{c}\text { X-YZ: } 4.0 \\
\text { A: } 4.8 \\
\text { C: } 2.8\end{array}$ & {$[\mathrm{Kw}]$} \\
\hline \multicolumn{2}{|l|}{ Tool clamp } & MAS BT40 [HSK] & \\
\hline \multicolumn{2}{|c|}{ Tool locking device } & Mas $2[-]$ & \\
\hline \multicolumn{2}{|c|}{ Tool loading capacity } & $20,32,48,105$ & [tools] \\
\hline \multicolumn{2}{|c|}{ Tool clamping diameter } & $\varnothing 90, \varnothing 125$ & {$[\mathrm{~mm}]$} \\
\hline \multicolumn{2}{|c|}{ Maximum tool length } & 240 & {$[\mathrm{~mm}]$} \\
\hline \multicolumn{2}{|c|}{ Maximum tool weight } & 8 & {$[\mathrm{~kg}]$} \\
\hline \multicolumn{2}{|c|}{ Maximum tool cutting force } & 7.8 & {$[\mathrm{Nm}]$} \\
\hline \multicolumn{2}{|l|}{ Choosing tools } & random & \\
\hline \multirow{2}{*}{ CNC machine } & Overall dimensions & $2160 \times 2715 \times 2950$ & {$[\mathrm{~mm}]$} \\
\hline & Weight & 7.700 & {$[\mathrm{~kg}]$} \\
\hline CNC system & OKUMA MU-400VA & & \\
\hline
\end{tabular}

\subsection{The choice of cutting tools and cutting regime}

In order to properly choose the cutting tools used, it is necessary to take into account some characteristics that are defining in the choice made, the nature of the processed material as well as the conditions under which the respective tool will cut (fig.1).

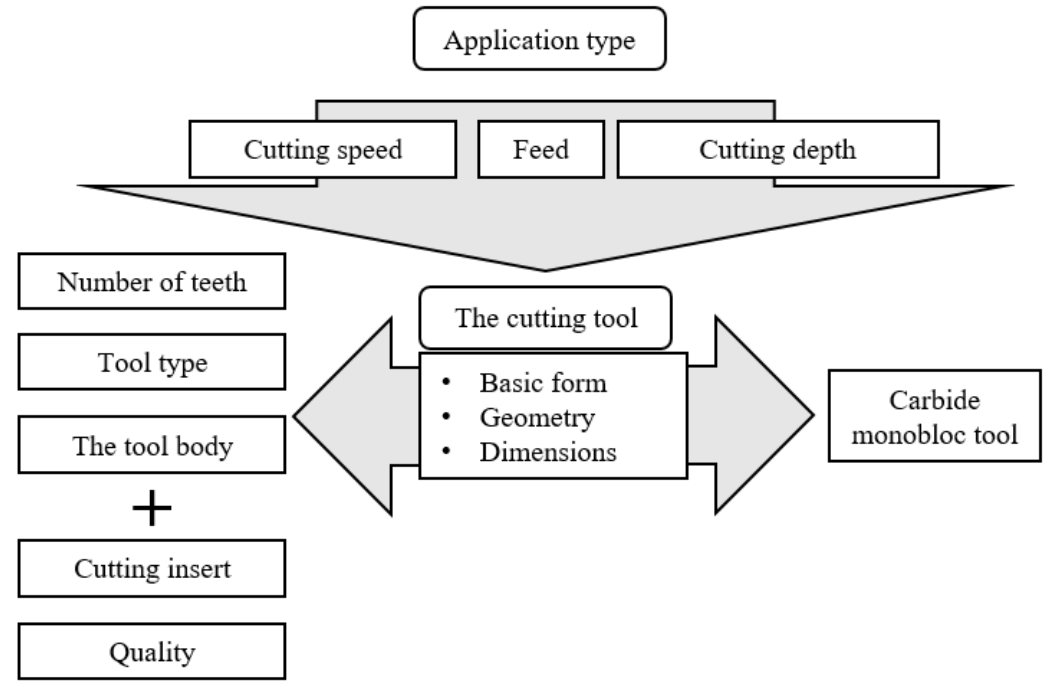

Fig. 1 Choice of the tool according to the executed operation. 
Another important criterion that is essential in choosing the cutting tool is depending on the geometric parameters of the cutting tool and the material of which it is composed, possibly the choice of a cutting tool with removable inserts or solid carbide tools. Another important issue that must be mentioned related to the choice of cutting tool is its tail, and the clamping system, mainly for the cases when the tool has to work in difficult to access places.

Depending on the material to be processed and the estimated temperatures in the contact area, it is important to choose the appropriate coating method used for the respective tool.

\section{Simulation of the rotational mold processing using PowerMill CAM application}

PowerMILL gives the user the flexibility to generate his own machine programs exactly as they wish. This wide range of options allows the operator to maximize milling efficiency, minimize the time the tool spends in the air, thus reducing the need for manual finishing and ensuring error-free machining. Despite this great range of strategies, PowerMILL is extremely easy to use, with all the options available in a single row of colored icons, arranged in the order that must be traversed to reach the final result, the toolpath [18].

For parametric model changes, the user can quickly generate new toolpaths without reentering tooling or machine strategy specifications.

Interactive processing allows the user to ensure that the most efficient processing method is used without having to wait for the complete calculation to be performed. A number of different strategies, from the wide range that PowerMILL has, can be compared using a high tolerance so that they can be calculated quickly.

Another feature is the ability to easily create tool libraries in PowerMILL, which can use all types of standard cutters. This allows companies to set standard cutting regimes for each cutting tool, making it easier for the inexperienced user to generate the tool path efficiently. The values can be changed automatically for different machines or materials that are used.

As a complement to these features, PowerMILL allows an increased computing speed for finishing. These options allow users to automatically generate machining paths needed to eliminate the addition left over from larger tool machining and optimize them to reduce manual finishing.

\section{Establishing the manufacturing route}

The use of numerically controlled machine tools and high-performance cutting tools reduces the number of operations. The manufacturing route realized is a specific one for the processing of the part on machine tools with numerical control, with multiple possibilities such as the execution on a single machine of all the operations necessary for the realization of the mold.

Energy consumption is much lower in the case of numerically controlled machine tools, the number of operators involved is also much lower, which leads to a significant reduction in execution costs. CNC consumes energy in a controlled way not constantly. The execution time decreases significantly both due to the shortening of the manufacturing route and to the high productivity of the numerically controlled machines, which allow the use of high cutting speeds.

A semi-finished cast aluminum AlCu6Mn cylindrical Ø500 × $381 \mathrm{~mm}$ was chosen.

The choice of cutting tools was made taking into account the geometric shape of the surface to be machined and the possibilities of reaching a certain area of the part to generate the surface with the roughness indicated in the drawing of the part. As a result, the cutting tools used in the operations necessary to make the mold are presented below.

The manufacturing route and cutting regimes of the first setup are as follows (figure 2): 

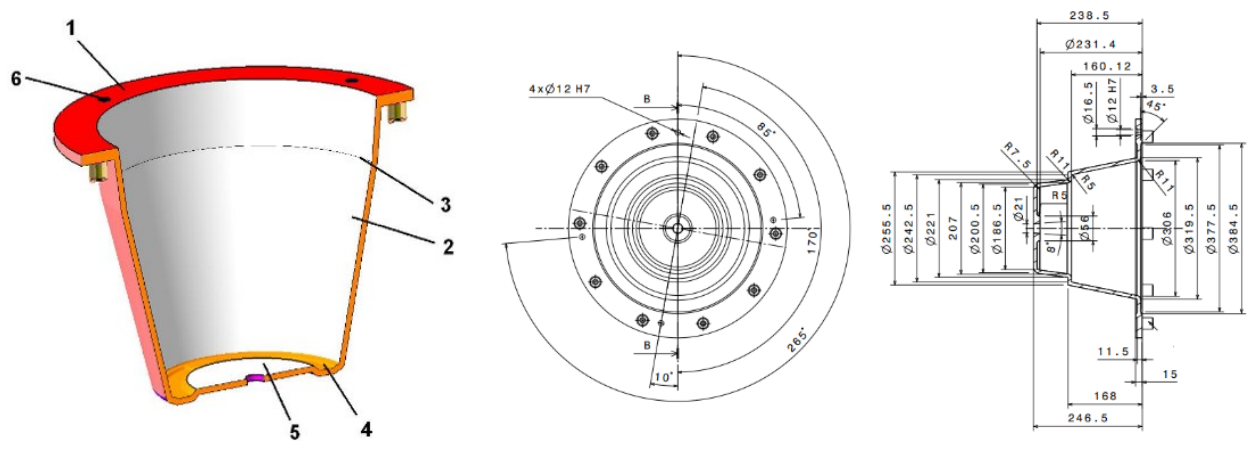

Fig. 2. First setup

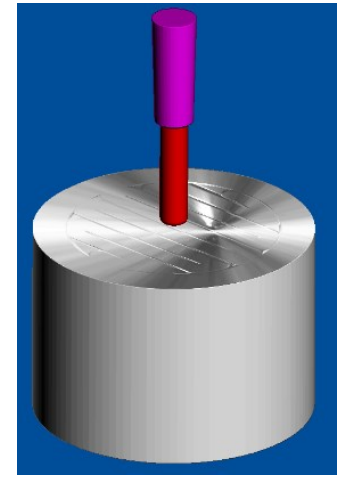

Fig. 3. Milling Surface 1

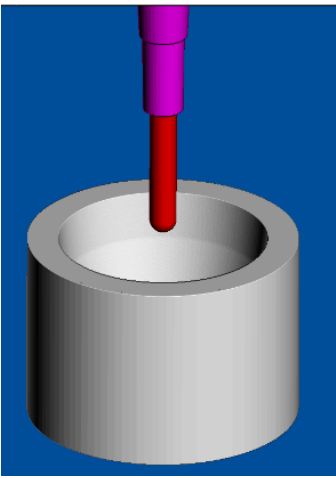

Fig. 4. Milling Surface 2

- $\quad$ Milling Surface 1 (figure 3):

$\circ$ Roughing milling:

- The cutting tool - SECO R220.29-0050-05.6A;

- Cutting insert - SECO RDHT 10T3M0-E04 H25;

- Cutting regime: $V_{c}=670[\mathrm{~m} / \mathrm{min}] ; f=0.35[\mathrm{~mm} / \mathrm{rev}], a_{p}=$ $5[\mathrm{~mm}]$

- Semi-finishing milling:

- The cutting tool - SECO R220.29-0050-05.6A;

- Cutting insert - SECO RDHT 10T3M0-E04 H25;

- Cutting regime: $V_{c}=720[\mathrm{~m} / \mathrm{min}] ; f=1.45[\mathrm{~mm} / \mathrm{rev}], a_{p}=$ $1[\mathrm{~mm}]$

- $\quad$ Milling Surface 2 (figure 4):

$\circ$ Roughing milling:

- The cutting tool - SECO R218.20-2.0050.3P-70.170;

- Cutting insert - SECO 218.20-250ER-ME12F40M;

- Cutting regime: $V_{c}=670[\mathrm{~m} / \mathrm{min}] ; f=0.6[\mathrm{~mm} / \mathrm{rev}]$.

○ Semi-finishing milling:

- $\quad$ The cutting tool - SECO R218.20-2.0050.3P-70.170;

- Cutting insert - SECO 218.20-250ER-ME12F40M;

- Cutting regime: $V_{c}=720[\mathrm{~m} / \mathrm{min}] ; f=1.4[\mathrm{~mm} / \mathrm{rev}]$. 


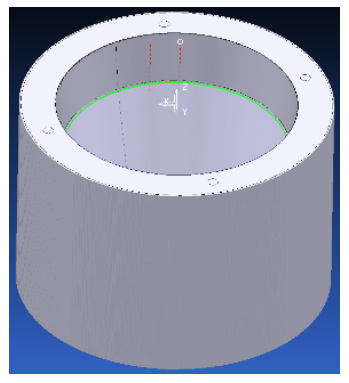

Fig. 5. Milling Surface 3



Fig. 6. Milling Surface 4

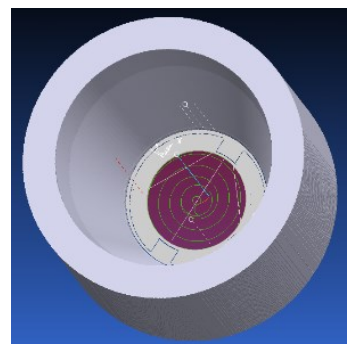

Fig. 7. Milling Surface 5

- $\quad$ Milling Surface 3 (figure 5):

○ Semi-finishing milling:

- $\quad$ The cutting tool - SECO J97VSL082;

- Cutting regime: $V_{c}=320[\mathrm{~m} / \mathrm{min}] ; f=0.384[\mathrm{~mm} / \mathrm{rev}]$.

- $\quad$ Milling Surface 4 (figure 6):

$\circ$ Roughing milling:

- The cutting tool - SECO J95L043-MEGA;

- Cutting regime: $V_{c}=150[\mathrm{~m} / \mathrm{min}] ; f=0.27[\mathrm{~mm} / \mathrm{rev}]$.

- Semi-finishing milling:

- The cutting tool - SECO J95L043-MEGA;

- Cutting regime: $V_{c}=320[\mathrm{~m} / \mathrm{min}] ; f=0.38[\mathrm{~mm} / \mathrm{rev}]$.

- $\quad$ Milling Surface 5 (figure 7):

$\circ$ Semi-finishing milling:

- $\quad$ The cutting tool - SECO R217.79 -1020.RE-09.2A;

- Cutting insert - SECO XOEX 090308FR-E05 H15;

- Cutting regime: $V_{c}=895[\mathrm{~m} / \mathrm{min}] ; f=0.32[\mathrm{~mm} / \mathrm{rev}]$.

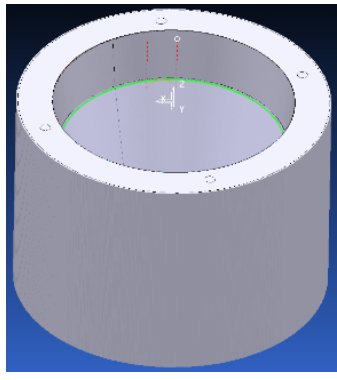

a)

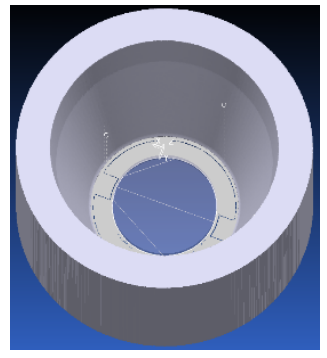

b)

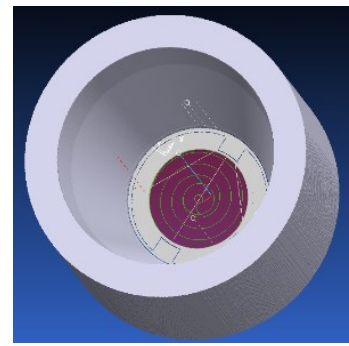

c)

Fig. 8. Milling Surface 6

- $\quad$ Milling Surface 6 (figure 8):

$\circ$ Centering (figure 8a):

- The cutting tool - SECO High speed steel centering K1111-5;

- Cutting regime: $V_{c}=148[\mathrm{~m} / \mathrm{min}] ; f=0.3[\mathrm{~mm} / \mathrm{rev}]$.

- Drilling (figure $8 \mathrm{~b}$ ):

- The cutting tool - SECO SD203-12.0-36-12R1;

- Cutting regime: $V_{c}=160[\mathrm{~m} / \mathrm{min}] ; f=0.42[\mathrm{~mm} / \mathrm{rev}]$.

$\circ \quad$ Finishing milling (figure $8 \mathrm{c}$ ):

- The cutting tool - SECO J40100;

- Cutting regime: $V_{c}=320[\mathrm{~m} / \mathrm{min}] ; f=0.38[\mathrm{~mm} / \mathrm{rev}]$.

In this research, the tool types were chosen, due to the fact that for the operation performed they falls within the recommendations of the manufacturer of SECO tools. 
The manufacturing route and the cutting regimes related to the second setup (Figure 9) are the following:

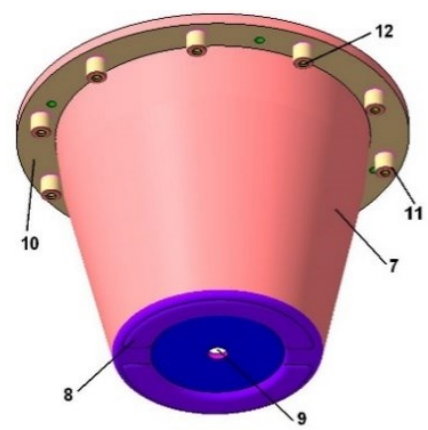

Fig. 9. The second setup

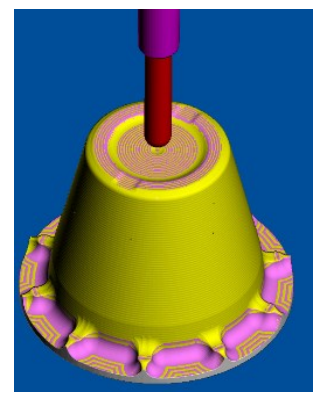

Fig. 10. Milling Surface 7

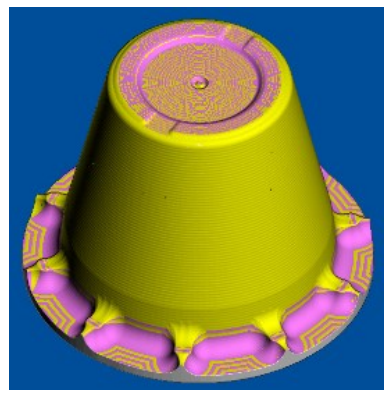

Fig. 11 Milling Surface 8

- $\quad$ Milling Surface 7 (figure 10):

$\circ$ Roughing milling:

- The cutting tool - SECO R218.20-2.0050.3P-70.170;

- Cutting insert - SECO 218.20-250ER-ME12F40M;

- Cutting regime: $V_{c}=670[\mathrm{~m} / \mathrm{min}] ; f=0.6[\mathrm{~mm} / \mathrm{rev}]$.

- $\quad$ Milling Surface 8 (figure 11):

○ Roughing milling:

- $\quad$ The cutting tool - SECO J95L043-MEGA;

- Cutting regime: $V_{c}=150[\mathrm{~m} / \mathrm{min}] ; f=0.27[\mathrm{~mm} / \mathrm{rev}]$.

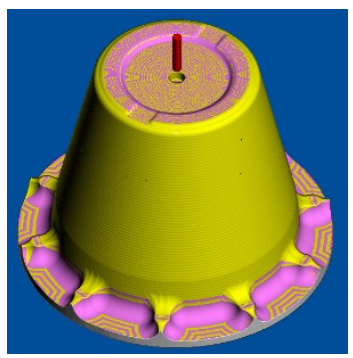

a)

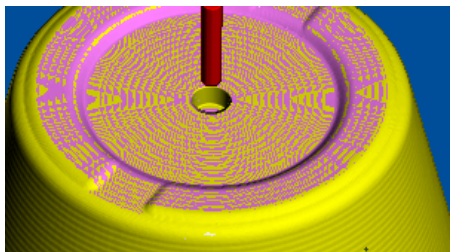

b)

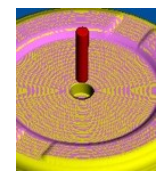

c)

Fig. 12. Milling Surface 9

- $\quad$ Milling Surface 9 (figure 12):

$\circ$ Centering (figure 12a):

- $\quad$ The cutting tool - SECO High speed steel centering K1111-5;

- Cutting regime: $V_{c}=148[\mathrm{~m} / \mathrm{min}] ; f=0.3[\mathrm{~mm} / \mathrm{rev}]$.

- Drilling (figure 12b):

- The cutting tool - SECO SD203-20.0-49-12R1;

- Cutting regime: $V_{c}=160[\mathrm{~m} / \mathrm{min}] ; f=0.54[\mathrm{~mm} / \mathrm{rev}]$.

- Semi-finishing milling (figure 12c):

- The cutting tool - SECO J95L164-MEGA;

- Cutting regime: $V_{c}=150[\mathrm{~m} / \mathrm{min}] ; f=1.53[\mathrm{~mm} / \mathrm{rev}]$. 


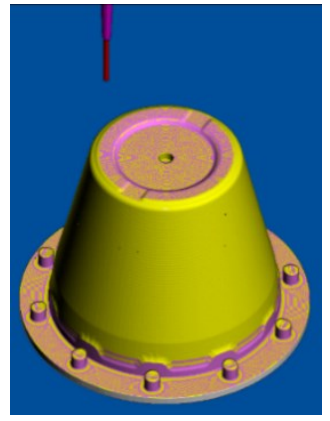

Fig. 13. Milling Surface 10

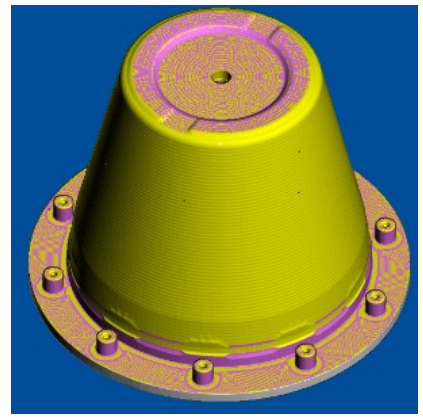

Fig. 14. Milling Surface 11

- $\quad$ Milling Surface 10 (figure 13):

$\circ$ Roughing milling:

- The cutting tool - SECO J97VSL102;

- Cutting regime: $V_{c}=150[\mathrm{~m} / \mathrm{min}] ; f=0.34[\mathrm{~mm} / \mathrm{rev}]$.

○ Semi-finishing milling:

- $\quad$ The cutting tool - SECO J97VSL102;

- Cutting regime: $V_{c}=150[\mathrm{~m} / \mathrm{min}] ; f=0.27[\mathrm{~mm} / \mathrm{rev}]$.

- Milling Surface 11 (figure 14):

○ Semi-finishing milling:

- $\quad$ The cutting tool - SECO J97041;

- Cutting regime: $V_{c}=320[\mathrm{~m} / \mathrm{min}] ; f=0.19[\mathrm{~mm} / \mathrm{rev}]$.

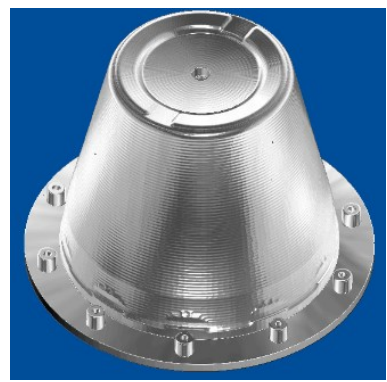

a)

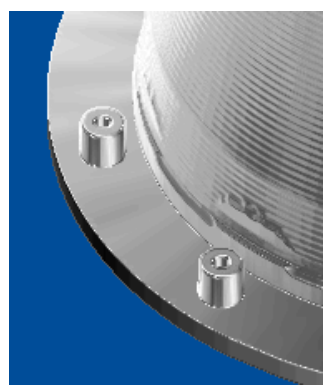

b)

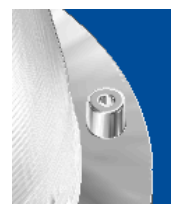

c)

Fig. 15. Milling Surface 12

- $\quad$ Milling Surface 12 (figure 15):

$\circ \quad$ Centering (figure 15a):

- The cutting tool - SECO High speed steel centering K1111-1;

- Cutting regime: $V_{c}=148[\mathrm{~m} / \mathrm{min}] ; f=150[\mathrm{~mm} / \mathrm{rev}]$.

- Pre-drilling (figure $15 b$ ):

- The cutting tool - SECO SD203-03281-106-0394R1;

- Cutting regime: $V_{c}=160[\mathrm{~m} / \mathrm{min}] ; f=0.32[\mathrm{~mm} / \mathrm{rev}]$.

$\circ \quad$ Threading (figure 15c):

- $\quad$ The cutting tool - SECO B 1217 TCN M10 6 H;

- Cutting regime: $V_{c}=250[\mathrm{~m} / \mathrm{min}]$.

\section{Conclusions}

In authors opinion the process of rotational molding is superior to other processing methods in terms of costs, as they are much lower. Another advantage of this process is that the breakeven point is much higher and very large parts can be processed. 
Generally, the products made by the rotational molding process are a real substitute for traditionally used materials and have a much lower weight.

Compared to other molding processes: such as injection molding or blowing molding, rotational molding has a number of advantages, for example making parts of higher precision and of any size at minimal cost.

Die modeling using computer aided design - CAD is a modern design method. This constructive design offers the possibility for designers to realize complex $3 \mathrm{D}$ projects starting directly from the real model.

Computer Aided Manufacturing (CAM) essentially is a software tool designed to support engineers and machinists in the processing of a wide variety of parts. CAM is a tool that allows the use of 3D models made based on computer aided design (CAD).

Nowadays, CNC-equipped machines are encountered in almost all phases and operations in various fields of manufacture, regardless of whether the processed object is made of metal, plastic or various wood.

Regarding the topic of this study, through experimental research it was found that by choosing and using the appropriate cutting tools and cutting inserts can be obtained:

- Reducing production costs and processing without supervision with confidence;

- Manufacturing of large series with stable performance from one batch of parts to another;

- Better machine operation due to stronger edges that reduce machine downtime due to plate damage;

- Less downtime for adjusting machine wear due to tool wear;

- Low maintenance due to the possibility of dry processing.

\section{References}

1. K. O. Ogila, M. Shao, W. Yang, J. Tan, EXPRESS Polym. Lett. 11, 778-798 (2017)

2. E. Jansri, N. O-Charoen, P, J. Polym. Eng. 38, 685-694 (2018)

3. E. O. Cisneros-López, A. A. Pérez-Fonseca, Y. González-García, D. E. RamírezArreola, R. González-Núñez, D. Rodrigue, J. R. Robledo-Ortíz, Adv. Polym. Technol. 37, 2528-2540 (2018)

4. R. J. Crawford, J. L. Throne, Rotational Molding Technology, Plastics Design Library/William Andrew Publishing, (USA, 2002)

5. A. Greco, A. Maffezzoli, S. Forleo, Thermochimica Acta, 582, 59-67 (2014)

6. M. D. Marrero, P. Hernández, L. Suárez, D. Pestana, A. Benítez, J. Martín, S. Rivero, E. Calero, ASME 2014 12th Biennial Conference on Engineering Systems Design and Analysis, (Copenhagen, Denmark, 2014)

7. E. O. Cisneros-López, M. E. González-López, A. A. Pérez-Fonseca, R. GonzálezNúñez, D. Rodrigue, J. R. Robledo-Ortíz, Compos. Interfaces, 24, 35-53 (2017)

8. A. Vignali, S. Iannace, G. Falcone, R. Utzeri, P. Stagnaro, F. Bertini, Polymers (Basel), 11, 624 (2019)

9. A. Greco, F. Ferrari, M. G. Buccoliero, G. Trono, Polymers (Basel), 11, 528 (2019)

10. F. J. Moscoso-Sánchez, E. Mendizábal, C. F. Jasso-Gastinel, P. Ortega-Gudiño, J. R. Robledo-Ortíz, R. González-Núñez, D. Rodrigue, J. Cell. Plast. 51, 489-503 (2015)

11. R. González-Núñez, F. J. Moscoso-Sánchez, J. Aguilar, R. G. López-González Núñez, J. R. Robledo-Ortíz, D. Rodrigue, Polym. Eng. Sci. 58, E235-E241 (2018)

12. J. R. Robledo-Ortíz, M. E. González-López, D. Rodrigue, J. F. Gutiérrez-Ruiz, F. Prezas-Lara, A. A. Pérez-Fonseca, J. Polym. Environ. 28, 1040-1049 (2020)

13. F. E. Hanana, C. Y. Desire, D. Rodrigue, Polym. Polym. Compos. 26, 299-307 (2018)

14. M. Barczewski, M. Szostak, D. Nowak, A. Piasecki, Polimery, 63, 772-784 (2018)

15. G. Höfler, R. J. T. Lin, K. Jayaraman, J. Polym. Res. 25, 132 (2018) 
16. E. O. Cisneros-López, A. A. Pérez-Fonseca, Y. González-García, D. E. RamírezArreola, R. González-Núñez, D. Rodrigue, J.R. Robledo-Ortíz, Adv. Polym. Technol. 37, 2528-2540 (2018)

17. http://www.okuma.co.jp/english/product/new/mu500va/index2.html, [Accessed 4 March 2021]

18. http://www.delcam.ro/index2.php?option=content\&do_pdf=1\&id=23, [Accessed 4 March 2021] 